\title{
Viewpoint
}

Dr Theofanis Fotis

Principal Lecturer Nursing

Course Leader MSc Health

School of Health Sciences/ University of Brighton

\section{Digital Health and the Perioperative Care}

According to the U.S. Food and Drug Administration 'the broad scope of digital health includes categories such as mobile health (mHealth), health information technology (IT), wearable devices, telehealth and telemedicine, and personalized medicine and is used by providers and other stakeholders in their efforts to reduce inefficiencies, improve access, reduce costs, increase quality, and make medicine more personalized for patients'. (FDA 2016) More recently, Paul Sonier, a digital health strategist and founder of the Linkedln digital health group with more than 40000 members, defined digital health as the convergence of the digital and genomic revolutions with health, healthcare, living, and society'. (Storyofdigitalhealth 2016 )

Over the past few years the term is continuously used in the media and it is hard not to pay attention on it, even if you do not have a special interest on digital technologies. The question though is if the new technologies are related with the perioperative care and if and when will they impact our everyday practice. The answer to both of these questions is definitely yes.

Reverting the order of the questions above in order to respond in more details, I will address firstly the, 'if'? The answer as I mentioned is absolutely yes! I am not answering driven by my personal interest but by looking at the government's agenda. This year, Health Secretary Jeremy Hunt during his speech at the NHS Confederation's annual conference in Manchester stated that 'Investment in IT can save time for doctors and nurses' and announced a government's investment of $£ 4.2$ billion in NHS technology over the next five years. The funding is earmarked for cyber security, information governance and consent, technology for out-of-hospital and integrated care, a new website - NHS.uk - apps, telehealth and free wi-fi across the NHS. 3 In addition, on 18 May 2016 Professor Jane Cummings, Chief Nursing Officer for England, launched 'Leading Change, Adding Value: a framework for nursing, midwifery and care staff' which is fully supported by Susan Aitkenhead, Head of Nursing NHS England. The framework offers 10 aspirational commitments and among others, no 10 states: 'We will champion the use of technology and informatics to improve practice, address unwarranted variations and enhance outcomes'. According to the framework and in order the NHS to meet this commitment, we need to become a technology-literate workforce, advocate technologies that may assist in reducing unwarranted variations in care, lead as early adopters of technology to improve health and enhance efficiency, empower and support individuals to improve health and self-managed care and use technology to manage workflow more 
effectively. (NHS England 2016) It is obvious that these developments referred across the sector and disciplines and they will affect, or better, already affecting our perioperative care also.

Answering the question of 'when'? will happen, well the answer could be yesterday! We are already experiencing technologies in the perioperative environment, robotic surgery, use of mobiles and iPads, electronic health records (EHRs) and picture archiving and communication systems (PACS). The benefits of using these technologies are widely demonstrated in the literature and among others, specifically for nursing, are (Imison 2016, Cipriano 2013, Smedley 2005):

- Improved patient outcomes through care continuum

- More time to be spent treating patients rather than wasting time managing processes

- Real time access to needed information for decision support

- Less time spent on administrative tasks and routine communication

- More time and increased ways to interact with and empower patients

Finally answering the question if there are related to perioperative care, digital health has much more to offer and there are many more technologies available, ranging from mobile applications/ software to robots to smart devices and others yet to come such as wearables and sensors. All the above with specifications ready to be applied in the perioperative environment. As examples I could refer to the following few only out of vast available:

Perioperative mobile apps (imedicalapps.com 2016)

' $M P R$ ', is the app version of the popular Monthly Prescribing Reference, a publication known for bite-size drug monographs on often-used prescription which includes a frequently updated drug database, medication charts, commonly used clinical calculators, and current medical news.

'iPhone accelerometer', which is a built-in accelerometer to objectively determine how well a patient's muscles are able to function.

'Regional Anaesthesia Assistant' app, which provides a guide of the common regional anaesthesia scenarios.

'PostopQRS' app, which helps patients and physicians measure post-operative surgery care.

'Block Buddy' medical app, which assists providers in performing ultrasound-guided regional anaesthesia.

'VLStreaming' app, by Airtraq, lets clinicians perform video laryngoscopy and intubation using the Airtraq device and any smartphone.

\section{Robots}


'Xenex' Germ-Zapping Robots which provide effective, fast and full spectrum UV disinfection in the perioperative environment.

'Veebot', which is an automating venepuncture device, using computer vision and robotics, making it safer for both patients and medical staff, and cost efficient for medical facilities.

\section{Wearables/ Sensors}

'evena' the eyes-on wearable technology which enhances vascular viewing through multispectral imaging for precise IV placement and record storage.

'vivi', a head-mounted display system designed specifically to help healthcare professionals monitor real time patient life-signs more effectively.

Devices that can measure air quality, temperature, humidity, atmospheric pressure, ambient light, background radiation and electromagnetic field strength, like the 'TZOA' and 'Lapka $P E M^{\prime}$.

The popular 'GoogleGlass' with multiple applications in education and monitoring.

The introduction and implementation of these new technologies and advancements are not coming without challenges. Just the opposite as the sector is walking on uncharted areas with limited regulations. The main challenges to be addressed during this fast paced changes include cyber security of the patient's data, leadership, education and engagement for both the patients and healthcare professionals.

So what will our role be in this new era of the proliferation and 'penetration' of digital technologies in our everyday perioperative practice? The guidance it has been given in the NHS England framework above, where it states among others that we need to 'lead as early adopters of technology'. As Susan Aitkenhead Head of Nursing NHS England stated in an interview by the British Journal of Healthcare Computing BJ-HC on 26/5/2016, 'There will be a significant cultural change as we want patients and practitioners to embrace moving into a paperless era'. 9. (ukehealthweek.com 2016)

A year earlier I presented my view on addressing this challenge. I talked about what I have called Digital Nursing: a disruptive model of nursing practice. Disruptive as it refers to "bedside" nurses who graduate with the knowledge to harness the benefits of digital health and protect against the dangers, in collaboration with IT professionals, in order to enhance the "human touch" against the fear of standing off the patient, referring to the need of a revolution rather than a cultural change and evolution of our practice. (www.cvent.com 2016)

As a closing point I would like to share Mark Brown's (Development Director, Social Spider $\mathrm{CIC}$ ) words from his speech 'Why Digital Technology Might be our Best Ally Rather than our Worst Enemy" given at London's Olympia as part of UK e-health week 2016: 'Not paying attention to digital technology doesn't mean it won't happen in health and care. It just means that the digital technology in health and care will be bought and built by people who 
understand the people sized problems of health and care less than we do. Digital technology is not a possible future, it's an unfolding present. Digital is already changing things. A change you choose is much less painful than a change forced upon you.' (The New Mental Health. 2016).

\section{References}

1. FDA. 2016 Digital Health [Online]. Available at:

http://www.fda.gov/MedicalDevices/DigitalHealth/default.htm [Accessed 5/8/2016]

2. Storyofdigitalhealth. (2016) Definition of Digital Health [Online]. Available at: http://storyofdigitalhealth.com/definition/ [Accessed 5/8/2016]

3. www.digitalhealth.net. (2016) Hunt announces $£ 4.2$ billion for NHS IT [Online]. Available at: http://www.digitalhealth.net/news/47167//hunt-announces\%C2\%A34.2-billion-for-nhs-it [Accessed 5/8/2016]

4. NHS England. (2016) Leading Change, Adding Value: a framework for nursing, midwifery and care staff.

5. Imison C, Castle-Clarke S, Watson R and Edwards N. (2016) Delivering the benefits of digital health care. Research summary. Nuffield Trust

6. Cipriano, P. F., et al. (2013) "The importance of health information technology in care coordination and transitional care." Nurs Outlook 61(6): 475-489.

7. Smedley, A. (2005) "The importance of informatics competencies in nursing: an Australian perspective." Comput Inform Nurs 23(2): 106-110.

8. www.imedicalapps.com. (2016) [Online]. Available at: http://www.imedicalapps.com/2016/04/mpr-app-drug-reference-app-review/\# [Accessed 5/8/2016]

9. ukehealthweek.com. (2016) [Online]. Available at: http://ukehealthweek.com/news.asp?info=NHS+needs+significant+cultural+change+ to+be+paperless [Accessed 5/8/2016]

10. www.cvent.com. (2016) [Online]. Available at: https://www.cvent.com/Events/ContactPortal/Pages/Custom.aspx?cid=706\&cwstub =03445170-be23-4395-ba47-a7ba9f8386d8 [Accessed 5/8/2016]

11. The New Mental Health. (2016) Just what *is* the role of digital tech in health and social care? \#EHWK16 [Online]. Available at: http://thenewmentalhealth.org/?p=221 [Accessed 5/8/2016] 